\title{
AM PULS DER
}

\section{MOTORENENTWICKLUNG}

Liebe Leserin, lieber Leser,

75 Jahre sind ein beachtliches Alter.

Dies gilt insbesondere für Zeitschriften, deren Wettbewerbsumfeld stets erheblichen Veränderungen unterworfen war und die sich daher immer wieder neu positionieren mussten - eine Gesetzmäßigkeit, bis heute mehr denn je gültig ist. Daher freut es uns als „Macher“ besonders, dass die MTZ Motortechnische Zeitschrift nicht nur auf eine große Vergangenheit zurückblickt, sondern auch der Zukunft gut gerüstet ins Auge schauen kann. Die MTZ war und ist das Sprachrohr der Motorenentwickler über die Grenzen Deutschlands hinaus. Das ist nicht allein das Verdienst ihrer Redakteure. Es sind vor allem die Autoren und Leser, die immer wieder die Zeit finden, uns mit Fachbeiträgen zu interessanten und bahnbrechenden Entwicklungen zu versorgen und die jeden Monat mit Spannung auf die nächste Ausgabe „ihrer“ MTZ warten. Dafür ein herzliches Dankeschön von der gesamten Redaktion!

Die MTZ hatte es sich von Anfang an zum Ziel gesetzt, ihre Inhalte immer am Puls der Motorenentwicklung auszurichten. Im Geleitwort zur ersten Ausgabe im März 1939 schrieb Prosper L’Orange, einer der Gründer, dass „.... eine das ganze Motorengebiet umfassende Zeitschrift notwendig ist, welche dem Motorenbauer einen Überblick über alle wichtigen Neukonstruktionen sowie über alle zu solchen brauchbaren Versuchsergebnisse, Werkstoffuntersuchungen usw. bietet ....". Dies ist neben dem steten Bestreben nach herausragender Qualität bis heute die große Konstante der MTZ.

Ein Blick durch die Ausgaben der mehr als sieben Jahrzehnte zeigt, dass viele Themen wiederkehren: Brennverfah- rensentwicklung, Einspritzsysteme, Reibungsminimierung und Kraftstoffe haben seit der ersten Ausgabe nichts von ihrer Aktualität eingebüßt. Hinzu traten später Themen wie elektronische Motorsteuerung, Emissionen und zuletzt die zunehmende Elektrifizierung des Antriebsstrangs.

Wir haben die Wissenschaftlichen Beiräte der MTZ eingeladen, Beiträge für dieses Sonderheft zu schreiben. Dank ihrer Unterstützung bietet das Jubiläumsheft einen Querschnitt durch die Motorenentwicklung mit historischen Rückblicken und klaren Zukunftsperspektiven: Klassische Motorenentwicklung steht neben Zukunftsantrieben, Pkw- und Nfz-Motoren finden gleichermaßen Beachtung, und Überblicksartikel schauen über den Tellerrand. Es ist damit eine echte MTZ: immer am Puls der Motorenentwicklung!

Ich wünsche Ihnen viel Spaß bei der Lektüre.

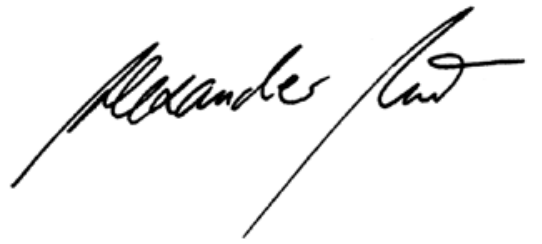

DR. ALEXANDER HEINTZEL, Chefredakteur Wiesbaden, 2. Juni 2014

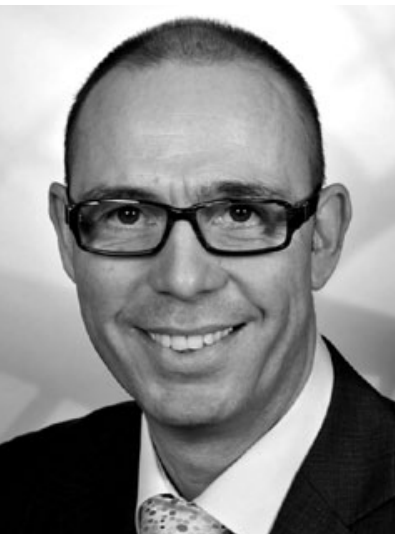

Wir

\section{entwickeln,} was bewegt

IAV - Ihr Partner

für Automotive Engineering 